\title{
Family Involvement in the Schools of Belize
}

\author{
Rachel K. Youngblom, Daniel Houlihan ${ }^{1}$ \\ ${ }^{1}$ Minnesota State University, Mankato, MN USA \\ Received: August 28, 2014 Accepted: October 16, 2014 Online Published: December 5, 2014 \\ doi:10.11114/jets.v3i1.601 URL: http://dx.doi.org/10.11114/jets.v3i1.601
}

\begin{abstract}
This study was conducted to better understand the level of involvement of families in Belize with the education of their children. It was anticipated that information from this broadly distributed survey might show areas of current strengths and weakness in the current system that might allow for future adjustments.
\end{abstract}

Keywords: family involvement, education, Belize

\section{Introduction}

Research that attempts to explore extraneous variables that may impact student achievement in developing countries is sparse. However, this is a topic that is emerging. The research that has been conducted demonstrates that there are some global consistencies and inconsistencies that effect children academically when compared to students within the United States (Cole \& Brown, 2002; Punamaki, Qouta, \& Sarraj, 2001). Based on these studies we know that family involvement is an important contributor to school success. However, global research that assesses family involvement in relation to academic achievement is sparse. Garbacz and Sheridan (2011) have noted the importance of assessing family involvement in schools on a global level. Tools such as the Family Involvement Questionnaire (FIQ) have shown value in measuring parent attitudes in a variety of settings and across a wide range of school activities (Fantuzzo, Tighe, \& Childs, 2000).

Family involvement has become an increasingly popular topic that has been validated through multiple studies and has shown to have a positive impact on student academic achievement (Christenson, Rounds, \& Gorney, 1992). Parent involvement has evolved over time to include "family" due to the inherent strengths of "families" that includes different individuals that may take on the caregiver role within a "family" system; such as siblings, grandparents, relatives, and many others who serve as significant adults in the lives of students.

Family involvement is often found to be highly prevalent when assessing effective schools and achievement gains have been noted to be significant when families are involved throughout the entire academic career of a student by supporting academic and social ambitions (Christenson et al., 1992). A study by Kagan (1984) also reports that the most effective type of family involvement entails home and school participation. This includes parents becoming involved with the governance of the school, school-based home instruction programs, and home learning activities such as reading (Christenson et al.). Parental involvement has also been shown to increase the quality of a child's education (Carlisle, Stanley, \& Kemple, 2005).

Christenson et al. (1992) noted four factors within families that have been found to influence student achievement. The first of those factors involves the parent's or caregiver's expectation of the student and perception of the student's attributes. A general conclusion can be made that high parent expectations can be correlated with high academic achievement. Scott-Jones (1984) also found that when parents had realistic and accurate expectations of their child, the child performed well on cognitive performance tasks. The second factor introduced describes the structure for learning within the home environment. This entails whether the student has the appropriate space to complete homework, functional lighting and proper materials (i.e., pencils, paper, crayons) and an established schedule. Parents play a significant role in the homework process by maintaining that these needs can be met.

The third factor discussed by Christenson et al. as an indicator of high academic achievement describes the home affective environment. This can be explained as the emotional environment within the home as well as the parent-student relationship. A positive parent-child relationship within the home is more likely to produce a student who demonstrates persistence at intellectual tasks and social competence. The fourth factor explained within the study describes discipline that is used within the home. Discipline refers to "the parenting methods used to control children's 
behavior" (Christenson et al., 1992, pg. 188). In short, characteristics of discipline measures within the home that are associated with high academic achievement involve setting clear guidelines, allowing independence, implementing rules, but also encouraging dialogue and compromise. The importance of family dialogue might be the least studied and understood factor.

Due to the complex relationship between family influences and academic achievement, more research is needed to look at specific variables that may influence student success. Many extraneous variables such as social economic status (SES), parent/caregiver educational level, gender, ethnicity and culture may also play a role that affects family involvement. Often, what is considered appropriate parent involvement differs between cultures (Carlisle et al., 2005) and parents may be unaware how to connect school-based expectations and values that may be different than those within the home (Coleman \& Churchill, 1997). For example, within some cultures, it is disrespectful to communicate with the teacher for fear that the teacher may believe you are questioning or second guessing their expertise (Carlisle et al.). Because each individual family has unique needs, priorities, and values, they may seek out and use resources differently (Xu \& Filler, 2008). When these familial variables are assessed, further interventions and collaboration between home and school may take place to promote student academic achievement.

Outside of tracking parent attendance at conferences, schools generally don't keep running tallies of parent involvement with their children or the schools. Likewise, benchmarks for parent involvement generally don't exist, although parent involvement is discussed by teaching staffs in schools all over the world. Appleseed (2006) has outlined problems associated with parents not being involved with schools in the cooperative education of children. For example, a lack of awareness of school expectations leaves parents not knowing if their child is achieving expected outcomes. In fact, they often feel their child is doing better than he or she is based on their own observations (Appleseed). The more parents are aware of teacher's expectations, the better they can track their child's performance at home and provide valuable feedback to the schools. Lastly, parents often can put schools with limited resources (such as those in developing countries) in touch with materials or resources they might not otherwise have access to.

\section{Method}

\subsection{Participants}

In collaboration with the Ministry of Education in the country of Belize, the researchers were under the understanding that a copy of the survey would be distributed to 240 randomly selected families throughout the 6 districts of Belize. Of 240 surveys distributed, 174 copies of the survey were completely filled out and returned to the researchers. An additional 11 surveys had the majority filled out and the completed items were used and items not completed were discarded.

\subsection{Measure}

The Family Involvement Questionnaire (FIQ) (Fantuzzo et al., 2000) was used to assess the extent and nature of the parent/caregiver's involvement of the child's education. The FIQ consists of 46 questions and responses are given on a Likert-type rating (Rarely, Sometimes, Often, Always). All questions are utilized to measure family involvement in three areas: school-based involvement, home-based involvement, and home-school conferencing. School-based involvement entails the extent that parents engage in activities involved with the school that will benefit their child (i.e., going on class trips or volunteering in the classroom). Home-based involvement reflects all that the parents do within the home to make an environment conducive to learning (i.e., assuring space to do homework; asking questions about school). Home-school conferencing describes the communication between school and parents that discusses anything related to the child (i.e., progress in school, student strengths and difficulties). The three parent involvement dimensions were assessed using Cronbach's alpha coefficient and shown to have good internal consistency as follows: School-Based Involvement, .85; Home-Based Involvement, .85; and Home-School Conferencing, .81 (Fantuzzo, McWayne, Perry, \& Childs, 2004).

\subsection{Procedure}

An effort was made to gauge the level of family involvement in the schools of Belize in order to further inform the Ministry of Education and schools of areas for improvement. In collaboration with the Ministry of Education, a survey was administered to families that contained demographic data and all questions related to the Family Involvement Questionnaire. The surveys were administered by mail, delivered to the household, or sent home with the student at school. Due to a clerical error, the front page of the survey complete with demographic data was not copied along with the rest of the survey. Therefore, demographic data was not retained; only the district in which the survey was retrieved was able to be determined. Surveys were received from four (4) of the six (6) districts in Belize. Family members were very helpful in their efforts to fill out the surveys and return them in a timely fashion. In the country of Belize, it is a widely held belief that family involvement in a child's education can be amongst the most significant factors in a child's 
success. The families were instructed to return the questionnaires with the student to school in where it would be retrieved by the student's teacher. The teacher would in turn mail or deliver the survey to the Ministry of Education. The Ministry of Education then sealed the questionnaires in a manila envelope and mailed them to the researchers.

The goal of taking samples from across Belize was to establish an understanding of the degree of involvement currently between family's and schools in Belize, and to establish a baseline for comparison moving forward in our efforts to improve the educational experience for all children in Belize. What follows is the presentation of the compiled data from this effort.

\section{Results and Discussion}

The means and standard deviations for the individual subscales of the Family Involvement Questionnaire can be viewed in Table 1. The mean is the collective average on a scale from 1 to 4 with scores nearer to 1 suggesting the need for improvement and scores above 3 and closer to 4 suggesting areas of current strength. The standard deviation reported on responses simply indicates how much responses varied. High standard deviations (higher than 1.00) suggest less agreement amongst those filling out the survey.

The study showed that on average, families in Belize report that they are Sometimes-Often engaged with their children's school involvement. This means that parents and/or caregivers feel that they often participate in activities that revolve around the school and/or their child's classroom and also interact with other parents from the school. Some of the specific areas that parents/caregivers reported a lack of involvement (Rarely-Sometimes) were: attending workshops or training provided by the school, volunteering in the child's classroom, talking with individuals in the child's school about training or career development opportunities for themselves, and meeting with other families from their child's classroom outside of school. As can be seen in Table 1, the involvement of parents in home with their child's education is very strong. This suggests that education is valued within the family units in Belize. Involvement in the schools themselves (School-Based Involvement) and in Home-School Conferencing (communication between parents and the schools) is comparatively weaker and suggests some specific areas that we might focus on for improvement. The means and standard deviations received for the individual questions related to the school-based involvement subscale can be seen in Table 2.

Table 1. Descriptive Statistics for Family Involvement Questionnaire Subscales

\begin{tabular}{lll}
\hline Subscale & Mean & SD \\
\hline School-Based Involvement & 26.81 & 7.16 \\
Home-Based Involvement & 57.48 & 10.07 \\
Home-School Conferencing & 40.94 & 11.22 \\
\hline
\end{tabular}

Table 2. School-Based Involvement

\begin{tabular}{lll}
\hline Related Subscale Questions & M & SD \\
\hline I attend parent workshops or training offered by my child's school. & 2.25 & 1.20 \\
I volunteer in my child's classroom & 2.35 & 1.22 \\
I participate in fundraising activities at my child's school & 3.10 & 1.02 \\
I go on class trips with my child & 2.69 & 1.19 \\
I participate in parent and family social activities at my child's school & 2.79 & 1.14 \\
I talk with other parents about school meetings and events & 2.55 & 1.10 \\
I talk with people at my child's school about training or career development & 1.80 & .99 \\
$\quad$ & & \\
$\quad$ opportunities for myself. & 2.42 & 1.08 \\
I attend organized family-school associations at my child's school & 2.49 & 1.13 \\
I talk about how my child is doing in school to family and friends & 3.21 & .90 \\
I meet with other families from my child's classroom outside of school & 1.94 & 1.06 \\
\hline
\end{tabular}

Note: $N=175-185$. Data completion varied depending on the question. Pairwise deletion was used.

On average, families also feel that they are Often involved with the child throughout the home environment. This describes how families feel that they help their children with their homework, spend time with their children at home and also engage in educational activities outside of school. Some of the specific areas that parents/caregivers reported a 
lack of involvement (Rarely-Sometimes) were, taking their child to a library and arranging times when their child's classmates can come to the home to play. Families reported high involvement (Often - Always) in areas of maintaining clear rules in the home, asking their children how their day was at school and helping children with their homework. The means and standard deviations for the individual questions related to the home-based involvement can be seen in Table 3.

Table 3. Home-Based Involvement

\begin{tabular}{|c|c|c|}
\hline Related Subscale Questions & $M$ & $S D$ \\
\hline I limit my child's TV and video watching & 3.09 & .98 \\
\hline I review my child's school work & 3.50 & .78 \\
\hline I take my child to the public library & 1.47 & .77 \\
\hline I take my child to school in the morning & 2.93 & 1.21 \\
\hline I keep a regular morning and bedtime schedule for my child & 3.40 & .93 \\
\hline I share stories with my child about when I was in school & 3.25 & .94 \\
\hline I take my child to places in the community to learn special things & 2.73 & 1.12 \\
\hline $\begin{array}{l}\text { I check to see that my child has a place at home where books or school materials are } \\
\text { kept }\end{array}$ & 3.50 & .89 \\
\hline I read with my child & 3.27 & .92 \\
\hline I bring home learning materials for my child (tapes, videos, books) & 3.01 & 1.04 \\
\hline I maintain clear rules at home that my child should obey & 3.58 & .74 \\
\hline I ask my child how his or her day was at school & 3.52 & .76 \\
\hline I arrange times at home when my child's classmates can come and play & 1.98 & 1.12 \\
\hline I pick my child up from school in the afternoon & 2.62 & 1.30 \\
\hline My child has chores to do at home. & 2.97 & 1.04 \\
\hline I do creative activities with my child (like singing, drawing, and story-telling) & 3.23 & .92 \\
\hline I spend time with my child working on math skills & 3.12 & .94 \\
\hline I help my child with homework & 3.57 & .74 \\
\hline I talk to my child about how school has helped me & 3.33 & .88 \\
\hline
\end{tabular}

Note: $N=175-185$. Data completion varied depending on the question. Pairwise deletion was used.

The average family also feels that they Sometimes-Often are involved in maintaining communication with their child's teacher. This describes how families communicate with the classroom teacher regarding how the student is doing in school, share concerns and accomplishments of the child, and also work to address potential problem behaviors and academic strengths and weaknesses of the child. This indicates how well teachers and parents are working together, and this is an area that can use some improving on. Some of the specific areas that parents/caregivers reported a lack of involvement (Rarely-Sometimes): suggesting classroom activities and school trips to the teacher, talking to the teacher about classroom rules, writing notes to the teacher or the teacher writing notes to the parents/caregiver to communicate about the child or school activities, talking to the teacher about personal and family matters that may affect the child's work at school, and talking to the teacher on the telephone. The means and standard deviations for the individual questions related to the home-school conferencing can be seen in Table 4. 
Table 4. Home-School Conferencing

\begin{tabular}{|c|c|c|}
\hline Related Subscale Questions & $M$ & $S D$ \\
\hline I attend interviews with the teachers to talk about my child's learning or behavior & 2.86 & 1.03 \\
\hline I contact the teacher or principal to get information & 3.04 & 1.00 \\
\hline I talk to my child's teacher about his/her daily school routine & 2.88 & 1.03 \\
\hline I suggest classroom activities and school trips to the teacher & 1.73 & .92 \\
\hline I talk to my child's teacher about the classroom rules & 2.17 & 1.13 \\
\hline I praise my child for his/her school work in front of the teacher & 2.62 & 1.15 \\
\hline I call the teacher if I am concerned about things that my child tells me about school & 3.08 & 1.09 \\
\hline I talk to the teacher about how my child gets along with his/her classmates in school & 2.73 & 1.02 \\
\hline The teacher and I write notes to each other about my child or school activities & 1.90 & 1.05 \\
\hline I talk to the teacher about my child's accomplishments & 2.98 & .97 \\
\hline I talk to my child's teacher about his/her difficulties at school & 3.05 & 1.04 \\
\hline $\begin{array}{l}\text { I talk with my child's teacher about school work he/she is expected to practice at } \\
\text { home }\end{array}$ & 2.99 & 1.01 \\
\hline $\begin{array}{l}\text { I talk with my child's teacher about our personal and family matters if it affects my } \\
\text { child's work at school }\end{array}$ & 1.92 & 1.15 \\
\hline I feel that teachers and principal encourage parents to be involved at school & 3.31 & .87 \\
\hline I talk with my child's teacher or principal about disciplinary problems & 2.55 & 1.19 \\
\hline I talk with my child's teacher on the telephone & 2.18 & 1.14 \\
\hline
\end{tabular}

Note: $N=174-185$. Data completion varied depending on the question. Pairwise deletion was used.

The results of this initial survey are very promising. They show that parents in Belize value education and wish to contribute to the welfare of their children. It also shows that there is some amount of communication going on between parents and the schools, but this is an area that we can work to improve. The more families and the schools can do to cooperate in the education of our children, the more outstanding the results will be. Future research would include obtaining the level of family involvement in addition to the academic success of the student and analyze the relationship between the two factors. Further, school-wide efforts and/or interventions could also be put into place to improve the home-school communication. Pre and post measures of student academic success could then be assessed for positive effects.

\section{References}

Appleseed. (2012). It takes a parent: Recommendations regarding the vital role of parents and guardians in achieving student and school success. Washington, DC: http://appleseednetwork.org/wp-content/uploads/2012/05/It-Takes-A-Parent.pdf

Carlisle, E., Stanely, L., \& Kemple, K. M. (2005). Opening doors: Understanding school and family influences on family involvement. Early Childhood Education Journal, 33(3), 155-162. http://dx.doi.org/10.1007/s10643-005-0043-1

Christenson, S. L., Rounds, T., \& Gorney, D. (1992). Family factors and student achievement: An avenue to increase students' success. School Psychology Quarterly, 7(3), 178-206. http://dx.doi.org/10.1037/h0088259

Cole, E., \& Brown, R. S. (2002). Psychological needs of post-war children in Kosovo: A preliminary analysis. School Psychology International, 23, 131-147. http://dx.doi.org/10.1177/0143034302023002912

Coleman, M., \& Churchill, S. (1997). Challenges to family involvement. Childhood Education, 73(3), 144-148. http://dx.doi.org/10.1080/00094056.1997.10522672

Fantuzzo, J., McWayne, C., Perry, M. A., \& Childs, S. (2004). Multiple dimensions of family involvement and their relations to behavioral and learning competencies for urban, low-income children. School Psychology Review, 33(4), 467-480.

Fantuzzo, J., Tighe, E., \& Childs, S. (2000). Family Involvement Questionnaire: A multivariate assessment of family participation in early childhood education. Journal of Educational Psychology, 92, 367-376. 
http://dx.doi.org/10.1037/0022-0663.92.2.367

Garbacz, S. A., \& Sheridan, S. M. (2011). A multidimensional examination of New Zealand family involvement in education. School Psychology International, 32, 600-615. http://dx.doi.org/10.1177/0143034311403034

Kagan, S. L. (1984). Parent involvement research: A field in search of itself. Boston, MA: Institute for Responsive Education.

Punamaki, R. L., Qouta, S., \& El-Sarraj, E. (2001). Resiliency factors predicting psychological adjustment after political violence among Palestinian children. International Journal of Behavioral Development, 25, 256-267. http://dx.doi.org/10.1080/01650250042000294

Scott-Jones, D. (1984). Family influences on cognitive development and school achievement. Review of Research in Education, 11, 259-304. http://dx.doi.org/10.2307/1167237

Xu, Y., \& Filler, J. (2008). Facilitating family involvement and support for inclusive education. The School Community Journal, 18(2), 53-71.Retrieved from http://www.adi.org/journal/fw08/xufillerfall2008.pdf

\section{(cc) EY}

This work is licensed under a Creative Commons Attribution 3.0 License. 